\title{
STUDY OF WOUNDS IN VICTIMS OF HOMICIDE BY FIREARMS AND EXPLOSIVES
}

Rajeev Kumar ${ }^{1}$

\section{HOW TO CITE THIS ARTICLE:}

Rajeev Kumar. "Study of wounds in victims of homicide by firearms and explosives". Journal of Evolution of Medical and Dental Sciences 2013; Vol. 2, Issue 44, November 04; Page: 8517-8539.

ABSTRACT: BACKGROUND: Firearms and explosives constitute convenient means of destroying human life from considerable distance. OBJECTIVE: Study of wounds in victims of homicide by fireams and explosives. METHODS: The present study comprised of one hundred cases of homicidal firearms and explosives injuries drawn from the medicolegal autopsies held in the mortuary of the department of Forensic Medicine. RESULTS: There was presence of firearm erntry wounds in all (100\%) victims and presense of exitwounds only in $61.36 \%$ Victims. In majority (61.36\%) of victims firearm exit wounds were present.One exit wound was present in 16(18.18\%) Victims. Two exit wounds in $17(19.31 \%)$ victims, three exit wound in $9(10.22 \%)$ victims and more then three firearm exit wounds in $12(13.63 \%)$ victims. It was revealed that in maximum $(46.59 \%)$ brain and meninges were injured, followed by pleura and lungs (20.45\%) pericardium and heart in 18.18 per cent. These were followed by ribs (15.90\%), liver in 13.63 per cent. Aorta (9.9\%), stomach (6.80), small intestine (5.68\%) and large intestine in 4.54 per cent. All (100.00\%) homicidal victims of explosive injuries showed burning, abrasions and contusions. Lacerations were seen in 91.66 percent victims. However, blackening was seen in 83.33 per cent and tattooing in 75 per cent victims. It was found in three fourth (75\%) of victims of fatal explosive injuries there were no other associated injuries by any weapon other than explosive. In one victim (8.33\%) associated injuries by firearm was present and that caused his death. However, in two victims (16.66\%) associated injuries (by fire arm and blunt weapon) were present but they were not fatal. In all 12 (100\%) victims recived injuries on multiple body parts amongst which injuries on chest were in 9 (91.66\%), neck (75\%), head (66.66\%), abdomen (66.66\%). Injuries on upper extremity was seen in 50 per cent and on the lower extremity in33.33 per cent. Findings on frequency of involvement of various internal organs and structures in the victim of homicides by explosives showed that in well over three fourth of victims(83.33\%) pleura and lungs were involved followed by pericardium and heart(75\%), ribs(75\%), aorta(66.66\%).In 58.33\% victims vessels in neck were involved and in $58.33 \%$ of victims pharynx were also involved. In $50 \%$ if victims oesphagus,theoric vertebrae and major abdominal blood vessels were involved.In $41.66 \%$ victims of explosive injuries,cervical vertebrae , thoracic cord,Pancreas,stomach,lumber vertebrae,spleen and bones of upper extremities were involved.In one third of victims (33.33\%) small intestine, large intestine,uraniry bladder,joints of upper extremity, muscles and vessels of lower extremity were involved.In only one fourth (25\%) of victim, bones and joints of lower extremity were injured. CONCLUSION: In view of the complexities created by the introduction of newer and newer improvised and conventional firearms and explosives in most of the areas, the establishment of various facts in a cases of firearm death, such as the type of weapon used, the range of firing, the direction of fire, the number of shots fired, wound of entry and exit and the damage to vital parts and the like, have become fraught with serious and many difficulties and complexities for the Forensic Pathologists and ballistic experts.

KEYWORDS: Firearm wounds, explosive wounds. 
INTRODUCTION: The situation and pattern of crime in India has become more serious. The socioeconomic and political system is generally regarded as responsible for present deteriorating crime situation.

The crime generally have been classified in adult and non adult or non juvenile group. The number of both crime have been found increasingly growing at a high growth rate since independence.

Educational development and difference of economic front represent specific structure of society in a country. In our country the present socio-economic structure shows that we are in high unbalanced level of socio-economic development.

There is low level of literacy and employment. Further the development status of rural and urban area reveals that there are more diversities and difference.

Criminal activities are related to different socio-economic factors in the areas were higher intensity of backwardness is found. Criminal activities have also been reported in high socioeconomic development. Urbanization and industrialization facilitate growth of crime at a higher intensity. It has also been reported that with the development of mass media criminal activities became more inten sive.

The low socio-economic profile of people indicate that there is exploitative mode of production that exist in society and which stimulates growth of crime.

In many sociological and criminological researches it is clearly found that the victim had been the main cause of crime. Hence in order to ascertain the cause of crime the victim should be considered.

A review of relevant literature would reveal that the incidence of homicide by the use of all kinds of weapons has risen substantially and steadily in the strife torn social orders that is being ushered in by fast industrialization and urbanization accompanied by highly intensified stress and strains of our modern civil existence.

Homicide means killing of a man by another and use of firearm and explosives have made it easier.Chinese were the first to discover gunpowder but it was the Mongols under the emperor Chingiz Khan who was reported to have used gunpowder to propel a projectile or a missile from somekind of a mechanical device- the primitive firearm.

Firearms have passed through continuous evolutionary changes and have established as the most popular instrument for committing homicide, whether during peace or in war time.

Firearms are the principal source of state power, as has been very aptly epitomized by none other than Mao-Tung, the great evolutionary leader of modern China that the "Political power flow from the barrel of gun".

Scientific interpretation of the various firearm wounds and the Identification of the gun with which these are inflicted are the most challenging tasks for the forensic pathologists.

Firearms and explosives constitute convenient means of destroying human life from considerable distance, providing opportunity to the offender to escape, it has been the weapon of choice for gangsters, terrorists, extremists, antisocial and anti-national elements for eliminating their victims. Its use is increasing in recent years because of easy availability due to manufacture of huge amount of arms, ammunition and explosives and free snuggling across the international borders. 
Firearms were involved in approximately two-thirds of all homicidal deaths in U.S.A. (Spitz 1973). These were used in many as 23,899 deaths from firearm fatalities in 1967 (Fatteh, 1974). Approximately 20,510 citizens were killed in 1975 in USA, out of which nearly half of the cases were caused by handguns (Hayes, 1978).

Use of firearm and explosives for homicide purpose is a worldwide phenomena and Var anasi in no exception to this. This is due to increasing number of hijacking, urban terrorism, dacoity, rioting, robberies, smuggling of drugs, political motivation, personal and group rivalry, quarrel over land, property, caste feuds and the like.

Homicide by firearm and explosives have become so common that Hardly a day or two passes without the news of such a death being flashed in the columns of the popular newspaper, $\mathrm{p}$ ss of industrialization with the resultant increase in social tension and strife and easy availability of technical knowledge and materials to make a firearms, have also contributed substantially to the use of firearm and bombs. The socio-economic loss in terms of valuable lives cut shorts and expenditure incurred for the treatment of the injured and rehabilitation of the disables have been great.

Forensic pathologist has vital role in pronouncing the cause of death due to firearm and explosion. He has to establish the wound of entrance, exit and track followed by the projectile. He has to trace out the missiles and the accompaniments such as wads and gunpowder, lodged in the wounds and preserving them carefully for sending to the ballistic expert for further opinion as needed, and also in stating the range and direction of firing.

The present study of the cases of homicide by firearm, and explosives based on the medicolegal autopsies carried out in the mortuary of the department of Forensic Medicine, Institute of Medical Sciences, Banaras Hindu University, Varanasi; was carried out with the view to study wounds in the victim of homicide by firearms and explosives in order to fill-up lacunae and also to add to the body of the knowledge regarding the cases, with a view to enable the forensic pathologists to help the scientific crime investigation and proper administration of criminal justice, in cases of homicides by the firearms and explosives that may be brought for trial in the Courts of justice by the investigative and law enforcing agencies.

REVIEW OF LITERATURE: Murder have long been associated with activities of criminal elements engaged in organized crimes. Such murders may be planned or disguised or bluntly brutal in order to dramatise the fate of the victim or victims among his family or associates, and to set an example. A staged killing may be designed to cover up the professional aspect of the killing, and an elaborate plan may be devised for the dispo sal of the body (Tedesch, 1977).

Miethe et al. (1994) studied "crime and its social context". They argued the major theories of criminality are rejected for their forces oh the behaviour of individual offenders and relatives neglect of aspect of the social environment that facilitate crime,for of which are discussed: Socioeconomic status, residential mobility, ethnic heterogenity and single parent families. These factors are integrated into a theory of crime that stresses the relationship between offenders victims and social context. Further, it is shown that such.

Indicators as population mobility, family disruption, public transportation and family income are significant predictors of crime rate in a given community.

It would seem easy to derive prediction about homicide using Durkehiem's (1897) concepts, accordingly low level of social regulation in society would be expected to lead to increased rates of 
all kind of deviant behaviour including homicide high level of social integration might lead to increased rates of homicides between friends and relatives in reaction to the frustration constraints of close inter-personalities. In contrast low levels of social integration might lead to increased rates of homicide between strangers.

Lambroso's positivism and the Darwinion Philosophy of human nature flourished during the last half of the 19th century. Lombroso, theory of a born methodological basic. Later on Lombroso modified his view and develop the positive approach which emphasized that crime, is a natural phenomenon caused by variety of factors (Multiple causation), Some of which are biological and other environmental.

Durkheim, however, theorizes that the most popular path to nowhere is biologism, according to which men violate the criminal code out of a hereditary, constitutional compulsion to do so. This view dies hard despite a hundred years of sterile speculation and misbegotten research (Singh, 1990).

Lester (1998) examined 53 nations in 1980 to see whether predictions based on Dukheimein theory of suicide and homicide, but a measure of social regulation was positively associated with suicide rate and negatively associated with homicide rate.

Friendlander (1947) reported that unfavorable environment play a part in criminal homicide but only as a precipitating cause that encourage murderous behaviour repressed in normal person.

A reanalysis of regional differences in homicide rate is conducted for two types of homicide, derived from the victim-offender relationship. A social structural, as opposed to subcultural, explanation is supported, but is found to have limitations. Social structural variables, particularly poverty, are shown to be important predictor of differences in primary homicide rates (generally involving family members or friends), but are less important in explaining variations in non-primary rate (those generally involving strangers) (Smith and Parker, 1980)

Homicide rates in western societies appears to have declined over the last several hundred years, but more recently, they experienced sharp and short term upsurges in the early $19^{\text {th }}$ century and in the last two decades (Gurr. 1981)

Blau and Blau (1982) found that economic inequality both between and within rates, is a significant predictor of homicide rates across metropolitan areas. They suggested that economic inequality engender, alienation, despair and pent up aggression which find expression in frequent conflict including a high incidence of criminal violence.

The theoretical orientation of recent research on con-variates of homicide rates are also often informed by one or both perspectives on the effect of age the first perspective is based on long standing observation of a greater propensity for teenager and young adults to commit more crimes, than individuals at other ages and is most recently articulated by Hirschi and Gottfredson (1983).

The second perspective is articulated by Cohen and Land (1987). Who noted that teenager and young adults not only commit crimes more frequently than those in those in other age groups but also are more likely to be victims. This preponderance is due to the participation of young persons in life styles at greater risk of victimization. Thus at the level of an aggregate unit the age structure Variate can have an effect both through the supply of victims of crime and the relative frequency of offenders. 
Massner (1989) argue that economic discrimination should have an appreciable effect on national homicide rate. Furthermore, the effect of discrimination should be greater then the effect of income inequality.

Two hypothesis are derived from Macro's structural theory concerning the relationship between economic discrimination and national homicide rates (1) level of economic discrimination should be positively related to national homicide rates (2) the level of economic discrimination should be astrologer predictor of homicides rates then in in income inequality.

The various statistics across different countries indicate that the incidence of murder, seems to be more in comparatively lesser developed countries than the highly developed ones.

All the available published data both from governmental and non-governmental sources indicate that homicide rate is rising in India and elsewhere despite severe punishment. In India society the annual rate of homicide is ranged from 2 to 3 per 100,000 population for the past ten years of so. The spurt in the incidence of murder rate in India has been increasing year by year. Nagpaul (1985) discovered that the volume of homicide per 100,000 population has increased from 2.50 in 1960 to 3.20 in 1980. Regional variation in the homicide rate is also of serious implications. Some states had a rate of 4.50 while others at the lowest of 1.2. According to bureau of police research and Development (1983) the volume of crime during 1977-81 lakh of population for Punjab was 81.5, the lowest among the state.

This data perhaps reflects the situation prior to the escalation of terrorism of Punjab. The incidence of murder and crime rates has dramatically increased in Punjab especially after 1982-83. This was happened particularly since the escalation of terrorists activities in Punjab.

The bureau of police Research and Development (1983) indicated that the highest number of crime cases in the year 1981 has been registered in Uttar Pradesh (1,851485n) in the country, closely followed by Maharashtra $(1,72,976)$ which is 12.5 per cent of the total cases registered in the country.

A total no of 27,269 cases were registered under the crime head murder in 1986 against a total no of 25,790 murder cases registered in 1985 in India recording an increase of 5.0 per cent over 1985. The highest mo of cases under this crime head was reported from Uttar Pradesh $(6,836)$ followed by Bihar (3,470), Madhya Pradesh (2650) and Maharashtra (2222).The volume of murder per lakh of population was very much higher than the national average of (3.6) in the states and union territories having tribal population viz. Arunachal Pradesh (6.5), Meghalaya (6.3), Mizoram (6.1), Tripura (5.4), Nagaland (5.2), Madhya Pradesh (4.5), Bihar(4.4) and Manipur (4.3). It was also higher in Punjab (5.9) and Uttar Pradesh (5.5) but it was much lower than the national average of (3.6) in Sikkim, Jammu and Kashmir.

Himachal Pradesh, Kerala, Chandigarh and Pondicherry in states and union territories during 1986 in comparison to 1985 were erratic (crime in India, 1986).

The incidence $(38,577)$ of murder in 1994 increased by 49.6 per cent over the decade $(1984$ 94), 5 percent the quinquennial average of $1989-93$ and by 0.9 percent over the previous year. The highest incidence $(10,776)$ of murder, constituting 27.9 percent of the total cases were reported from Uttar Pradesh, Bihar also reported significant number $(5,098)$ of murder cases (crime in India, 1994). 
Locations or place of Incidence: In Pokorny's (1965) study of 419 homicide victims, 41.9\% occurs in the home and $58.1 \%$ outside the home, out of which $13.8 \%$ took place in bedroom, $3.6 \%$ in kitchen, $7.6 \%$ in living room, $26.1 \%$ in highways and $3.6 \%$ cases in other commercial places.

Of the 1392 victims of homicidal firearm deaths reported by Faltch et al. (1974), determination of location of shooting was possible in only 666 cases (51.54\%) out of which 355 (53.30\%) occurred inside and $40(6 \%)$ outside the private houses while $91(13.66 \%)$ cases took place at such places as bars, night clubs and poolrooms, $15(2 \%)$ at the service stations, 19 (2.8\%) at the victim's place of work and the remaining 127 (19.06\%) at miscellaneous places that included church and cemetery.

Out of the 82 homicidal firearm fatalities studied by Gupta et al. (1979), 47 cases occurred in the homes and 35 cases on fields and roads.

Parts of Body Injured: In their series of 274 cases of homicide by firearms, Gonzales et al (1954) reported that $25 \%$ had been shot in the abdomen, $23 \%$ in the chest and only $10 \%$ in the head $7 \%$ were shot in the spine, $3 \%$ in the neck and $2 \%$ over the extremities. In the remaining $30 \%$ more than one bullet was encountered.

Frank Zimsing (1968) analysed 34 homicidal firearm deaths and showed that $44 \%$ involved the chest, $18 \%$ ab domen $32 \%$ head, while $3 \%$ involved back and shoulders.

Fattch et al. (1974) found that out of the 741 cases of firearm deaths, wounds in the chest (front and back) were in 383 (51.2\%) cases, it was the head and neck in 179 (24.2\%) cases and over the abdomen, extremities and buttocks respectively in 123 (16\%), 13 (1.9\%) and $3(0.4 \%)$ cases. In $40(5.4 \%)$ cases the total wounds were inflicted at more than one of the above sites.

In a series of 82 cases of homicidal firearm deaths studies by Gupta et al. (1979) it was found that entry wounds were located in front in 49 cases and on back in cases and over the sides in 10 cases. Entry wounds were located in head and neck in 18 cases, 30 in chest, 21 in abdomen and 13 in upper and lower extremities. Than study also revealed that in 29 instances pleura and lungs were involved, pericardium and heart in 25 cases, liver in 20 cases, stomach and intestines in 26 and brain and meanings were involved in 4 cases.

Das Gupta et al. (1983) study at Varanasi comprising 372 homicidal victims found that in $133(35.75 \%)$ cases head and neck were affected, upper extremity in $56(15.05 \%)$ and lower extremity in 87 (23.38\%) of cases. They also found that heart and aorta were injured in $54(14.54 \%)$ victims, lungs in 76 (20.43\%), liner. Kidney, spleen, GIT and abdominal aorta in 98 (26.35\%) and there were multiple injuries over the body in 27 (7.25\%) cases.

Number of Shots Fired: In their series of 274 cases of homicide by firearms, Gonzales et al. (1954) reported that the majority were shot with a single shot. There were only 4 victims having multiple shots.

In 82 cases of firearm fatalities studied by Subramanyam et al. (1978), there was only one entry wound in 40 (4078\%) cases, two in 13 (15.85\%), three in $5(6.09 \%)$ cases and more than three entry wounds in 24 (29.26\%) cases. In a series of 82 case of homicidal firearm deaths studies by Gupta et al. (1979) these was only one entry wound in 32 (35.95\%) cases, two in 26 (29.21\%), three in $14(15.73 \%)$ cases and more than wound in 10 (11.23\%) cases, a combination of revolver and shotguns. 
Multiple Wounds of Entrance and Exit by a Single Bullet: This occurs when a single bullet passes through and through the apposed body parts such as through the arm into the chest and again coming out of the chest and passes through the arm; or a bullet may pass through and through a body in the lap of another and may thereafter re-enter the body of the mother holding her. The same thing may happen when two or more persons are standing close to each other or when a person in either sitting or kneeling while shot form behind and above (Poison, 1973) or when a person is hit on the side of the thigh or a leg while standing.

Track taken by bullet through the body: The track is the pathway taken by the bullet from the entry wound to the site of lodgment or exit of the bullet. It helps to determine the direction of the flight of the bullet.

A resume of the missile path through the body should be given in relation to the planes of the body eg. the wound track passes from front to back, from left to right and slightly downwards.

Direction of the track should be done very carefully. A low velocity bullet is generally deflected during its passage through the body, so the identification of the track becomes very difficult (Adelson, 1977). The soft tissues and organs tend to dissipate energy in radial waves whereas a solid bone has the tendency to be shattered as energy dissipated radially from the height of impact (Modi).

Track in Heart: Gunshot wounds of the heart can be fatal immediately or rapidly as a result of hemorrhage or myocardial disruption. Other potentially lethal consequences include cardiac tamponade or damage to coronary vasculature (Demath, 1968). Bullet holes in heart walls may be small and slit like or large and ragged depending upon whether the bullet entered the heart in systole or diastole. Occasionally if the pericardial defect in large, a perforating injury usually results in massive haemothorax. If the pericardial defect does not permit ready communication with pleural cavity death often results from cardiac tamponade with pericardial cavity containing 200-500 ml of blood (Adelson, 1953).

Track in Large Vessels: They look like stellate lacerations or dissipation or slit like defects at the site of entry and exit. Adventitial hemorrhage in usually profuse at the traumatised site (Damuth, 1968).

Track in Lung: In bullet wounds, the track of damage through the lung is far wider than the diameter of the projectile itself. These are generally accompanied by haemothorax and interparenchymal bleeding. Haemo pneumothorax may also be present. Track in lung are usually ragged and haemorrhagic in appearance containing spicules of bone from fractured rib carried in by the blast wave of the bullet (Moritz, 1944).

Track in Liver: They usually appear as ragged laceration, irregular tracks or defects with great amount of parenchymal damage. Entry and exit wounds are usually stellate in appearance, but exit is considerably larger than entrance defect (Petty, 1969). This is accompanied with profuse intraperitoneal hemorrhage.

Track in Spleen: Spleen struck by a missile usually presents ragged capsular lacerations with extensive parenchymal destruction and traumatic infarct accompanied with profuse intraperitoreal bleeding (Sowell, 1961). 
Track in Kidney: They show ragged laceration and fragmentation. If the patient survives for hours or longer traumatic infarcts appear at the site of injury with profuse retroperitoneal bleeding (Knight, 1968).

Track in GIT: Bullet or L.G. ball or buckshot perforation of the GIT are usually surrounded by subserosal, intramuscular, submucosal and intraluminal bleeding. Leakage of visceral contents is source of peritonitis in victims who survived sufficiently long (Petty, 1969).

Track in Pancreas: Bullet perforation and laceration of the pancreas are accompanied by bleeding and fat necrosis. Latter is common when the victim survives for atleast several hours (Piedeliense, 1957).

Track in Pregnant Uterus: It is not normally fatal. Kracke (1963) reported a case of congenital paraplegia following bullet injury to the spine while in utero: delivery by caesarean section at the 28, ${ }^{\text {th }}$ weeks.

Track in Brain and Spinal Cord: A bullet usually creates a fusiform track, lined by ragged, macerated tissue while passing through brain substances. The track ordinarily contains fragments of brain tissue, blood clot and sometimes spicules of bone. Brain substance adjacent to the track present focal and confluent petechiae accompanied by subdural and subarachnoid hemorrhages specially when a large vessel is injured. One bullet may produce two tracks in brain if the missile rebounded or ricocheted off the inner table after making its exit from the brain and then re-entered at a different angle. This occurs in about $20 \%$ of bullet wounds of the head (Sowel, 1961).

Passage of bullet through vertebral column and spinal canal invariably results in injuries to the spinal coral, which ranged from concussion through superficial lacerations to transaction (Poison, 1973).

\section{MATERIAL AND METHODS:}

Material: The present study comprised of 100 (one hundred) cases of homicidal firearms and explosives injuries drawn from the medicolegal autopsies held in the mortuary of the department of Forensic Medicine, Institute of Medical Sciences, Banaras Hindu University, Varanasi, U.P., India, during the period from 1st July 1999 to $30^{\mathrm{M}}$ Nov. 2000, accompanied by sufficient number of relevant persons who were thoroughly interviewed at the time of autopsy on the body of deceased victim of homicide by firearm and explosives.

For the study relevant questionnaires schedule were prepared to collect various data, Socioeconomic factors, data about incidence of fatal firearm and explosive death, data about medicolegal crime investigation and evidential data etc. These cases were studied for the history of the cases, their epidemiological characteristics eg. age, sex, community character etc. nature, distribution and types of injuries including their medicolegal aspects.

Methods: The various data relating to the cases were collected from sources as under :

a. examination of inquest reports and connected papers.

b. interviewing the police personnel accompanying the cases.

c. interviewing the relatives, friends and neighbors of the deceased, and

d. the autopsy examination paper. 
The various data pertaining to each case was collected by the methods as indicated above so as to provide information on the following points:

1. History as regards date, time and place

2. Epidemiological features

A. in Regard of Firearm and Explosives Involved

a. Type of shot gun (single/double) rifle, revolver, pistol country made Explosives: Disruptive/Blast effect/Burn

b. Number of weapons used,

c. How many shots were fired

B. Environmental Data

a. Date and time of incidence

b. Place of incidence

(i) Indoor

(ii) Outdoor

c. Whether empty cartridge, shots, pellets etc. were recovered from the scene.

\section{A. Nature of firearm and explosive injuries and the related findings were obtained by}
a. Gross observation made at post-mortem examination
b. Number of injuries
c. Entrance and exit wounds,
d. Dimension of wounds
e. Area affected or site of the wounds
f. Track of the wounds, bodily structures and organs involved
g. Frequency of involvement of body parts
h. Type and number of missile recovered
i. Nature of immediate effects,
j. Nature of delayed effects
k. Fatal period
I. External post-mortem findings
m. Internal post-mortem findings

B. Presence of other injuries were also studied as to their nature site, size, severity etc.

4. The following medicolegal aspects of the cases were noted from the history, examination of inquest reports and other connected paper, from gross observation made at post-mortem examination.
a. Whether the firearm and explosive injuries were ante-mortem or postmortem in nature
b. How many times the deceased was shot
c. Which one of the injurieswerefatal
d. The range of firing
e. Type of weapon used infiring
f. Fatal period: how long thevictim survived after receiving the injury
g. Contribution of associated injuries to the fatal effects
h. Cause of death as revealed at post-mortem examination 
The various data regarding the cases collected by the methods as mentioned above were compiled using standard proforma and were then studied and analysed.

The results obtained from the study have been presented as under the observation.

OBSERVATION AND RESULTS: In the present study, a total of 100 cases of homicide by firearm and explosives drawn from the medicolegal autopies of Varanasi area including Chandauli carried out in the memory od Department of Forensic Medicine of Institute of Medical Sciences, Banaras Hindu university, Varanasi, During the period from 1.7.99 to 30.11.2000 (17 months).

\begin{tabular}{|l|c|c|}
\hline \multicolumn{1}{|c|}{ Types of injuries } & Numbers of cases & Percentage \\
\hline Entry wound & 88 & 100.00 \\
\hline Exit wound & 54 & 61.36 \\
\hline Wad and disc abrasions & 4 & 4.54 \\
\hline Wad and disc lacerations & 2 & 2.27 \\
\hline $\begin{array}{l}\text { Missiles recovered from the body of } \\
\text { victims }\end{array}$ & & \\
\hline (i) Shots/pellets & 20 & 22.72 \\
\hline (ii) Bullet & 14 & 15.90 \\
\hline (iii) Wad and Dics & 13 & 14.77 \\
\hline $\begin{array}{l}\text { Table 1 : Presence of entry wounds, wound injury, exit wounds and } \\
\text { missiles recovered from the body in the homicidal firearm victims. }\end{array}$
\end{tabular}

Table above shows presence of firearms entry wounds in all (100\%) victims and presence of exit wounds only in $61.36 \%$ Victims. Wad and disc abrasion was seen in $4.54 \%$ and wad and disc laceration in $2.27 \%$ victims. However, in 20 victims $14.00 \%$ and bullet in 14 victims $15.90 \%$.

\begin{tabular}{|c|c|c|c|c|}
\hline & & & Number & Percentage \\
\hline I & No exit wound with & & 34 & 38.63 \\
\hline & (a) One entry wound & 27 & & \\
\hline & (b) Two entry wounds & 2 & & \\
\hline & (c) Three entry wounds & 1 & & \\
\hline & (d) More then three entry wounds. & 4 & & \\
\hline II & One exit wound with & & 16 & 18.18 \\
\hline & (a) One entry wound & 9 & & \\
\hline & (b) Two entry wounds & 2 & & \\
\hline & (c) Three entry wounds & 1 & & \\
\hline & (d) More then three entry wounds. & 4 & & \\
\hline III & Two exit wound with & & 17 & 19.31 \\
\hline & (a) One entry wound & 6 & & \\
\hline & (b) Two entry wounds & 6 & & \\
\hline & (c) Three entry wounds & 3 & & \\
\hline & (d) More then three entry wounds. & 2 & & \\
\hline IV & Three exit wound with & & 9 & 10.22 \\
\hline
\end{tabular}




\section{ORIGINAL ARTICLE}

\begin{tabular}{|l|l|c|c|c|}
\hline & (a) One entry wound & 4 & & \\
\hline & (b) Two entry wounds & 1 & & \\
\hline & (c) Three entry wounds & 2 & & \\
\hline & (d) More then three entry wounds. & 2 & & \\
\hline $\mathrm{V}$ & More then three exit wounds with & & 12 & 13.63 \\
\hline & (a) One entry wound & 5 & & \\
\hline & (b) Two entry wounds & 3 & & \\
\hline & (c) Three entry wounds & 2 & & \\
\hline & (d) More then three entry wounds. & 2 & & \\
\hline & Table 2: No of entry wound via-a-vis no of exit \\
wounds on the body of homicidal fire arm victims.
\end{tabular}

Table above shows that in majority (61.36)\% of victims firearm exit wounds were present. One exit wound was present in 16(18.18\%) Victims. Two exit wounds in 17(19.31\%) victims, three exit wound in $9(10.22 \%)$ victims and more then three firearm exit wounds in $12(13.63 \%)$ victims. The no of entry wounds exceeded those of exit wound as under. There was no exit wounds in $34(38.63 \%)$ victims with one, two, three, and more then three entry wounds. There was one exit wounds with more then one entry round in $7(7.95 \%)$ victim, two exit wound with more then two entry wounds in 5(5.68\%) victims, and three exit wounds with more then three entry wounds 2 $(2.27 \%)$ victims.

Numbers of exit wounds exceeded that of entry wounds as under: there were two exit wounds with one entry wounds in $6(6.81 \%)$ victim and three fire arm exit wounds with less then three entry wounds in 5 (5.68\%) victims and more then three exit wounds with three and less than three entry wounds in $10(11.36 \%)$ victim. However, both the entrance and exit wounds exceeded three in no in $2(2.27 \%)$ victims.

\begin{tabular}{|c|l|c|c|c|}
\hline Orange & \multicolumn{1}{|c|}{ Structures } & Number & Percentage & Total No. \\
\hline Head & Scalp & 1 & 1.13 & 47 \\
\hline & Skull & 5 & 5.68 & \\
\hline & Brain \& meaning & 41 & 46.59 & \\
\hline Neck & Soft tissues & 3 & 3.40 & 7 \\
\hline & Vessels & 2 & 2.27 & \\
\hline & Vertebrae & 2 & 2.27 & \\
\hline Chest & Ribs & 14 & 15.90 & \\
\hline & Pericardium and heart & 16 & 18.18 & 60 \\
\hline & Pleura \& lungs & 18 & 20.45 & \\
\hline & Aorta & 8 & 9.90 & \\
\hline Abdomen & Spinal cord and vertebrae & 4 & 4.54 & \\
\hline & Liver & 12 & 13.63 & \\
\hline & Spleen & 2 & 2.27 & \\
\hline & Kidney & 3 & 3.40 & 34 \\
\hline
\end{tabular}


ORIGINAL ARTICLE

\begin{tabular}{|l|l|c|c|c|}
\hline & Panaceas & 2 & 2.27 & \\
\hline & Stomach & 6 & 6.80 & \\
\hline & Small intestine & 5 & 5.68 & \\
\hline & Large intestine & 4 & 4.54 & \\
\hline Upper Extremities & Muscles & 10 & 11.34 & \\
\hline & Vessels & 4 & 4.54 & \\
\hline & Bone & 3 & 3.40 & 19 \\
\hline & Joints & 2 & 2.27 & \\
\hline Lower Extremities & Muscles & 8 & 9.09 & \\
\hline & Vessels & 3 & 3.40 & 14 \\
\hline & Bone & 2 & 2.27 & \\
\hline & Joints & 1 & 1.13 & \\
\hline & Table 3: Frequency of involvement of internal organs \\
\\
and structures in victims of homicide by firearm.
\end{tabular}

Table given above reveals the frequency of involvement of various internal organs and structural in homicidal firearm injuries. It is revealed that in maximum (46.59\%) brain and meninges were injured, followed by pleura and lungs (20.45\%) pericardium and heart in 18.18 per cent. These were followed by ribs (15.90\%), liver in 13.63 per cent. Aorta (9.9\%), stomach (6.80), small intestine $(5.68 \%)$ and large intestine in 4.54 per cent.

\begin{tabular}{|l|c|c|}
\hline External features & Number & Percentage \\
\hline Burning & 12 & 100.00 \\
\hline Blackening & 10 & 83.33 \\
\hline Tattooing & 9 & 75.00 \\
\hline Abrasions & 12 & 100.00 \\
\hline Contusions & 12 & 100.00 \\
\hline Lacerations & 11 & 91.66 \\
\hline
\end{tabular}

Table 4: External findings on victims of homicide by explosives

\begin{tabular}{|l|c|c|}
\hline \multicolumn{1}{|c|}{ Associated injuries } & Number & Percentage \\
\hline Absent & 9 & 75.00 \\
\hline Present and fatal & 1 & 8.33 \\
\hline Present but non fatal & 2 & 16.66 \\
\hline
\end{tabular}

Table 5 : Incidence of associated fatal and non fatal injuries by weapons other than explosive.

associated injuries (by fire arm and blunt weapon) were but the present but they were not fetal.
Table given above reveals that all (100.00\%) homicidal victims of explosive injuries showed burning, abrasions and contusions. Lacerations were seen in 91.66 percent victims. However, blackening was seen in 83.33 per cent and tattooing in 75 per cent victims.

\begin{tabular}{|c|c|c|}
\hline Location & Number & Percentage \\
\hline Head & 8 & 66.66 \\
\hline
\end{tabular}




\section{ORIGINAL ARTICLE}

\begin{tabular}{|l|c|c|}
\hline Neck & 9 & 75.00 \\
\hline Chest & 11 & 91.66 \\
\hline Abdomen & 8 & 66.66 \\
\hline Upper extremity & 6 & 50.00 \\
\hline Lower extremity & 4 & 33.33 \\
\hline Multiple body parts & 12 & 100.00 \\
\hline
\end{tabular}

Table 6: Distribution of explosive injuries on different body parts of victims of homicide by explosive.

\begin{tabular}{|c|c|c|c|}
\hline Organ and structure & & Number & Percentage \\
\hline \multirow[t]{3}{*}{ Head } & Scalp & 8 & 66.66 \\
\hline & Skull & 8 & 66.66 \\
\hline & Brain and meninges & 7 & 58.33 \\
\hline \multirow[t]{5}{*}{ Neck } & Soft tissues & 9 & 75.00 \\
\hline & Vessels & 7 & 58.33 \\
\hline & Vertebrae & 5 & 41.66 \\
\hline & Oesophagus & 6 & 50.00 \\
\hline & Pharynx & 7 & 58.33 \\
\hline \multirow[t]{6}{*}{ Chest } & Ribs & 9 & 75.00 \\
\hline & Pleura and lungs & 10 & 83.33 \\
\hline & Pericardium and heart & 9 & 75.00 \\
\hline & Aorta & 8 & 66.66 \\
\hline & Spinal cord & 5 & 41.66 \\
\hline & Vertebrae & 6 & 50.00 \\
\hline \multirow[t]{11}{*}{ Abdomen } & Liver & 8 & 66.66 \\
\hline & Spleen & 5 & 41.66 \\
\hline & Kidney & 6 & 50.00 \\
\hline & Pancreas & 5 & 41.66 \\
\hline & Stomach & 5 & 41.66 \\
\hline & Small intestine & 4 & 33.33 \\
\hline & Large intestine & 4 & 33.00 \\
\hline & Mesentery & 3 & 25.00 \\
\hline & Urinary bladder & 4 & 33.00 \\
\hline & Major Vessels & 6 & 50.00 \\
\hline & Vertebrae & 5 & 41.66 \\
\hline \multirow[t]{4}{*}{ Upper extremities } & Muscles & 6 & 50.00 \\
\hline & Vessels & 6 & 50.00 \\
\hline & Bones & 5 & 41.66 \\
\hline & Joints & 4 & 33.33 \\
\hline
\end{tabular}




\begin{tabular}{|l|l|c|c|}
\hline Lower extremities & & & \\
\hline & Muscles & 4 & 33.33 \\
\hline & Vessels & 4 & 33.33 \\
\hline & Bones & 3 & 25.00 \\
\hline & Joints & 3 & 25.00 \\
\hline \multicolumn{2}{|l}{$\begin{array}{r}\text { Table 7: Frequency of involvement of internal organs } \\
\text { and structures in victims of homicide by explosives. }\end{array}$}
\end{tabular}

Table given above reveals the frequency of involvement of various internal organs and structures in the victim of homicides by explosives. It is seen that in well over three fourth of victims (83.33\%) pleura and lungs were involved followed by pericardium and heart (75\%), ribs (75\%), aorta (66.66\%). In 58.33\% victims vessels in neck were involved and in 58.33\% of victims pharynx were also involved. In $50 \%$ if victims oesophagus, theoric vertebrae and major abdominal blood vessels were involved. In $41.66 \%$ victims of explosive injuries, cervical vertebrae, thoracic cord, Pancreas, stomach, lumber vertebrae, spleen and bones of upper extremities were involved. In one third of victims (33.33\%) small intestine, large intestine, urinary bladder, joints of upper extremity, muscles and vessels of lower extremity were involved. In only one fourth (25\%) of victim mesentery, bones and joints of lower extremity were injured.

\begin{tabular}{|l|c|c|}
\hline \multicolumn{1}{|c|}{ Splinters } & Numbers & Percentage \\
\hline Nails & 7 & 58.33 \\
\hline Chips of metal alloy & 8 & 66.66 \\
\hline Glass fragments & 5 & 41.66 \\
\hline
\end{tabular}

Table given above shows that in over majority $(66.66 \%)$ of victims pieces of metal alloy were recovered from the body like brain, heart, lungs, and other internal organs. In $58.33 \%$ victims

Table 8: Splinters recovered from the body of homicidal explosive injury victims. nails were recovered and in less then half (41.66\%) victims glass fragments were recovered.

\begin{tabular}{|l|c|c|}
\hline \multicolumn{1}{|c|}{ Medical aid } & Number & Percentage \\
\hline Not hospitalized & 11 & 91.66 \\
\hline Hospitalized and operated & 1 & 8.33 \\
\hline Hospitalized and not operated & Nil & - \\
\hline \multicolumn{2}{|c|}{$\begin{array}{l}\text { Table 9: Medical aid received by the } \\
\text { victims of homicide by explosives. }\end{array}$} \\
\hline
\end{tabular}

Table given above clearly shows that almost all 11(91.66\%) victims could not be hospitalized.Only one victim (8.33\%) could be hospitalized and operated upon. None of the victim were not operated upon hospitalization.

\begin{tabular}{|c|c|c|}
\hline Place of death & Number & Percentage \\
\hline Scene of crime & 8 & 66.66 \\
\hline Hospital & 1 & 8.33 \\
\hline On way to hospital & 1 & 8.33 \\
\hline Not known & 2 & 16.66 \\
\hline
\end{tabular}

Table 10: Place of death of victim of homicide by explosives. 
DISCISSION: For the present study, a total of 100 cases of homicide by firearms and explosives were taken from the medicology autopsies of Varanasi area that were carried out in the mortuary of department of forensic medicine, Institute of medical sciences, Banaras Hindu University, Varanasi during the period from 1st July 1999 to 30th Nov 2000. These were studied and analyzed with special reference to wounds in the victims of homicide by firearms and explosives.

\section{Presence of Entry Wounds, Wad Injuries, Exit Wounds and Missiles Recovered From the Body of Victims:}

In our study (Table 1) while entry wounds were present in all (100\%) of our cases, only 54 (61.36\%) of the cases show exit wounds, the possible reasons for this have already been discussed in the foregoing paragraphs.
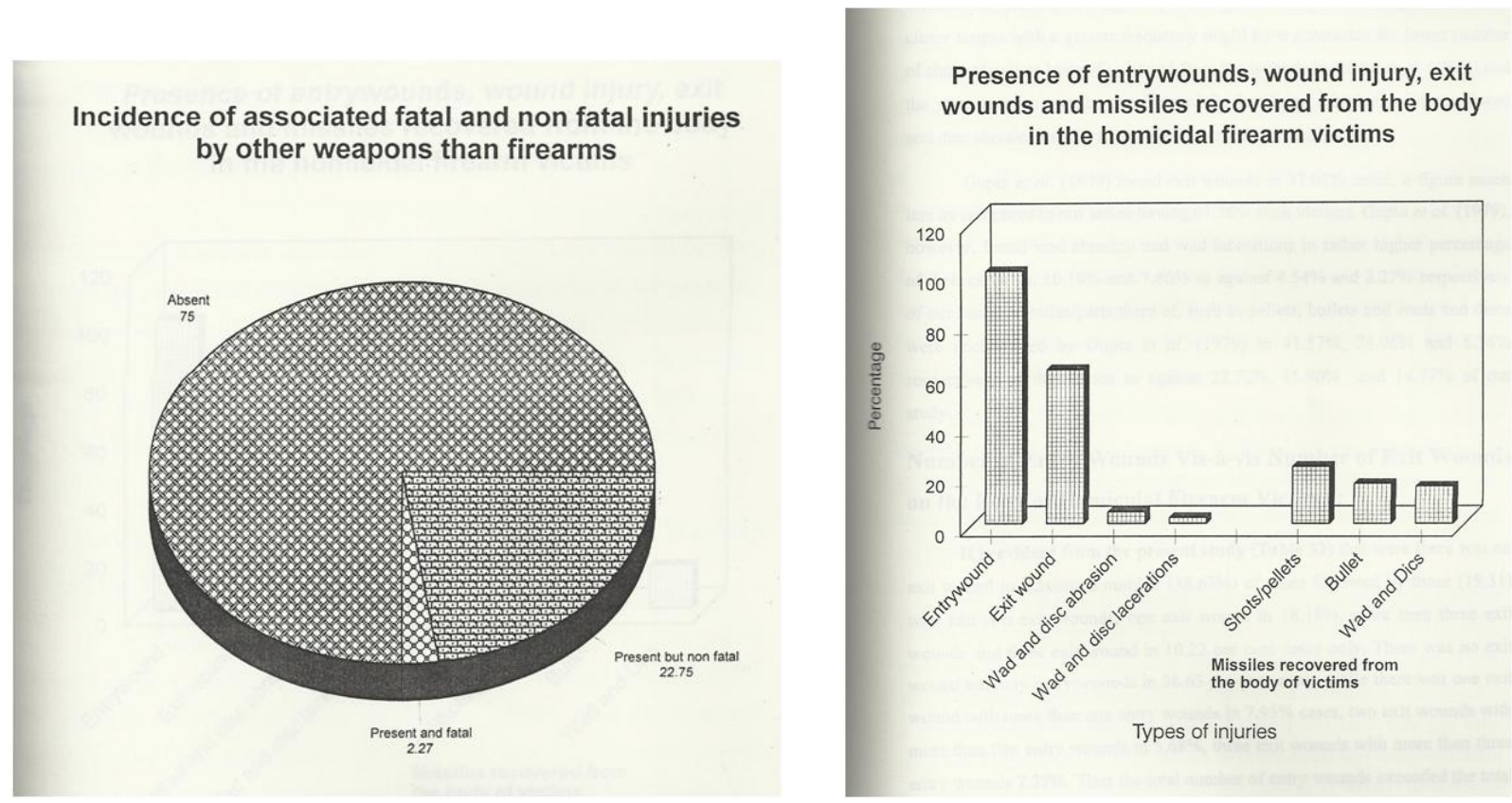

There were ward and disc abrasion in $4.54 \%$ cases and wad and disc lacerations in 2.27 per cent, cases Missiles i.e. shots/pellets, bullets and wad and discs were recovered from the body of $22.72 \%, 15.90 \%$ and $14.77 \%$ victims respectively. A higher percentage of shotgun discharge fired from closer ranges with a greater frequency might have accounted for lower number of shots of pellets being discovered from the wounds in Gupta et al. (1979) and the same reasons may be put forward for justifying a higher incident of wad and disc abrasions and wad and disc laceration in their series.

Gupta et al. (1979) found exit wounds in $37.08 \%$ cases, a figure much less as compared to our series having 61.36\% such victims. Gupta et al. (1979), however, found wad abrasion and wad lacerations in rather higher percentage of their cases i.e. $10.10 \%$ and $7.86 \%$ as against $4.54 \%$ and $2.27 \%$ respectively of our cases. Missiles/parts there of, such as pellets, bullets and wads and discs were encountered by Gupta et al. (1979) in 41.57\%, 26.96\% and 6.74\% respectively of their cases as against $22.72 \%, 15.90 \%$ and $14.77 \%$ of our. study. 
Number of Entry Wounds Vis-a-vis Number of Exit Wounds on the Body of Homicidal Firearm Victims: It is evident from the present study (Table 2) that were there was no exit wound in maximum number (38.63\%) of cases followed by those (19.31) who had two exit wounds, one exit wound in $18.18 \%$, more than three exit wounds and three exit wound in 10.22 per cent cases only. There was no exit wound but only entry wounds in 38.63 per cent cases, while there was one exit wound with more than one entry wounds in $7.95 \%$ cases, two exit wounds with more than two entry wounds in $5.68 \%$, three exit wounds with more than three entry wounds $2.27 \%$. Thus the total number of entry wounds exceeded the total number of exit wounds in as much as $54.53 \%$ cases while exit wounds were found in $61.37 \%$ of victims as against $38.63 \%$ who had no any exit wound.

Further we found that Shotguns, firing small pellets were used in as much as $40 \%$ of victims of homicidal fire arm injuries. Shotgun pellets more often than not, fail to produce any exit wound except at very close or contact range and over thin body parts. Shotgun pellets produce multiple exit wounds for each pellet when fired from close or contact range. So exit wounds were present in $61.37 \%$ of victim as against $38.63 \%$ victims with no exit wounds. The relative high frequency of exit wounds as compared to the entry wounds in the present study may be accounted for by the fact that shot guns were used in as much as $40 \%$ victims and that too, mostly at contact or close range. Rifled firearms also produce exit wounds when fired from close or near range as was noted in the present study. Apart from the standard shotguns such as 12 bore, the improvised or country made guns are often used to fire a 12 bore cartridge containing multiple pellets rather than a single bullet. These country made firearms are very effective at close and contact range and pellets fired from such weapon usually produced an exit wound.

Frequency of Involvement of Internal Organs and Structures in Homicidal Firearm Fatalities: In the present study (Table 3) the internal organs and structure of chest were most frequently involved by the firearm discharges (60), followed by head (47), abdomen (34), upper extremities (19), lower extremities (14) and neck (7). If we consider the chest and abdomen together, they constituted the trunk or the largest mass of the human body indicating their vulnerability to firearm discharges.

Involvement of trunk was more than head and neck in both the series even though assailants might be somewhat more tempted to aim the shots at the head and/or neck of their victims in view of number of vital structures clustered together in these two contiguous body parts, these are much less liable to take the shots in view of their much smaller size as compared to the trunk. Lower extremities for obvious reasons of being non-vital, were least often chosen as target for fatal homicidal shots by the assailants.

External Findings on Victims of Homicide by Explosives: In the present study (Table 4) burning, abrasions and contusions were seen in all 12 (100\%) victims of explore. Lacerations were seen in as much as 91.66 per cent victims. However, blackening was seen in 83.33 per cent and tattooing in 75 per cent victims. It is to be noted that since gun powder was used in the country made bombs along with nails, chips of metal and alloy; abrasions, bruises and burning was seen in all the victims. Blackening was seen in $10(83.33 \%)$ victims due to gun powder. However, tattooing was seen in 9 (75\%) victims because of unburn! and partially burnt powder along with dust being driven into the dermis. Laceration usually punctured laceration was seen in almost all (11 or 91.66\%) victims.

Journal of Evolution of Medical and Dental Sciences / Volume 2/ Issue 44/ November 04, 2013

Page 8532 


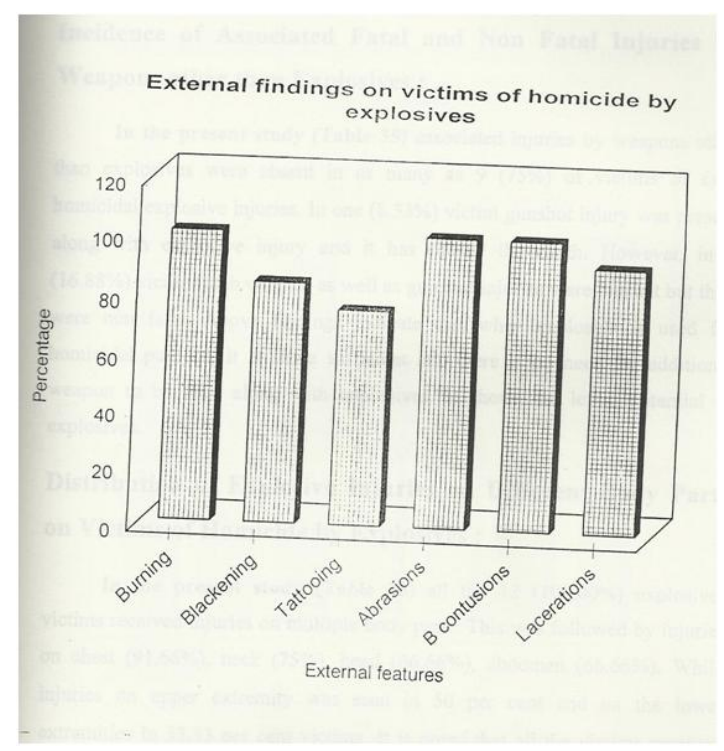

Incidence of Associated Fatal and Non Fatal Injuries by Weapons other than Explosives: In the present study (Table 5) associated injuries by weapons other than explosives were absent in as many as 9 (75\%) of victims of fatal homicidal explosive injuries. In one (8.33\%) victim gunshot injury was present along with explosive injury and it has caused the death. However, in 2 (16.88\%) victims stab wounds as well as gunshot injuries were present but they were non fatal. Above findings indicate that when explosive is used for homicidal purpose, it is alone sufficient and there is no need for additional weapon to be used along with explosives. It shows the lethal potential of explosives.

Distribution of Explosive Injuries on Different Body Parts on Victims of Homicide by Explosives: In the present study (Table 6) all the 12 (100.00\%) explosives victims received injuries on multiple body parts. This was followed by injuries on chest (91.66\%), neck (75\%), head (66.66\%), abdomen (66.66\%). While injuries on upper extremity was seen in 50 per cent and on the lower extremities in 33.33 per cent victims. It is noted that all the victims received injuries on multiple body parts. This is because of larger area of destruction of explosive as compared to firearm cases, which has narrow area and usually target single body part or structure. Even when the victim is away from the source of point of explosion, he may suffer blast lung injury and die. Amongst multiple body parts, injuries on chest was seen in most (91.66\%) of the victims. This shows that assailants commonly aimed to damage chest area, as many vital organs are likely to be injured at this part of body. 


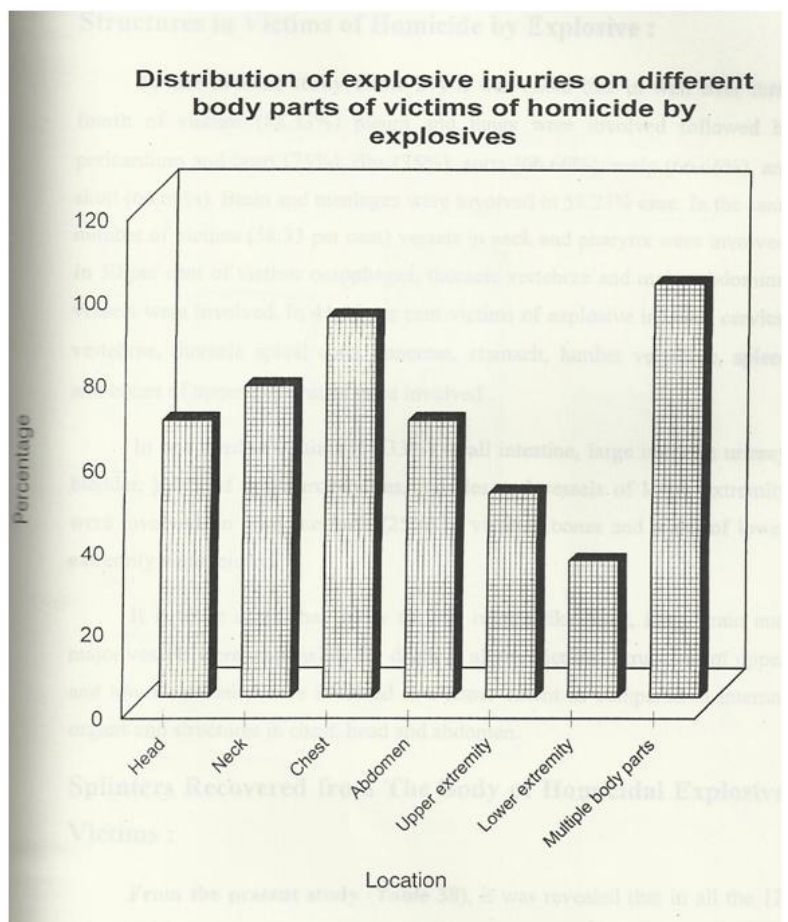

Frequency of Involvement of Internal Organs and Structures in Victims of Homicide by Explosive: In the present study (Table 7) it was noted that in well over three fourth of victims (88.33\%) pleura and lungs were involved followed by pericardium and heart (75\%), ribs (75\%), aorta (66.66\%), scalp (66.66\%), and skull (66.66\%). Brain and meninges were involved in 58.23\% case. In the same number of victims (58.33 per cent) vessels in neck and pharynx were involved. In 50 per cent of victims oesophagus, thoracic vertebrae and major abdominal vessels were involved. In 41.66 per cent victims of explosive injuries, cervical vertebrae, thoracic spinal cord, pancreas, stomach, lumber vertebrae, spleen and bones of upper extremities were involved.

In one third of victims (33.33\%) small intestine, large intestine urinary bladder, joints of upper extremities, muscles and vessels of lower extremity were involved. In only one-forth (25\%) of victims, bones and joints of lower extremity were injured.

It is to be noted that injury to vital organs like heart, lung, brain and major vessels were responsible for death in all the victims. Structures of upper and lower extremity were involved to a lesser extent as compared to internal organs and structures in chest, head and abdomen.

Splinters Recovered from The Body of Homicidal Explosive Victims: From the present study (Table 8), it was revealed that in all the 12 (100\%) such victims country made bombs were used. It usually contained gunpowder, nails, chips of metal allow and glass fragments.

In $8(66.66 \%)$ victims chips of metal alloy were recovered form vital as well as non-vital part of the body and nails were recovered from 7 (58.33\%) victims. However, glass fragments were found in $5(41.66 \%)$ victims. Splinters were lodged in vital and non-vital part of the body and were responsible for deaths of most of the victims. 


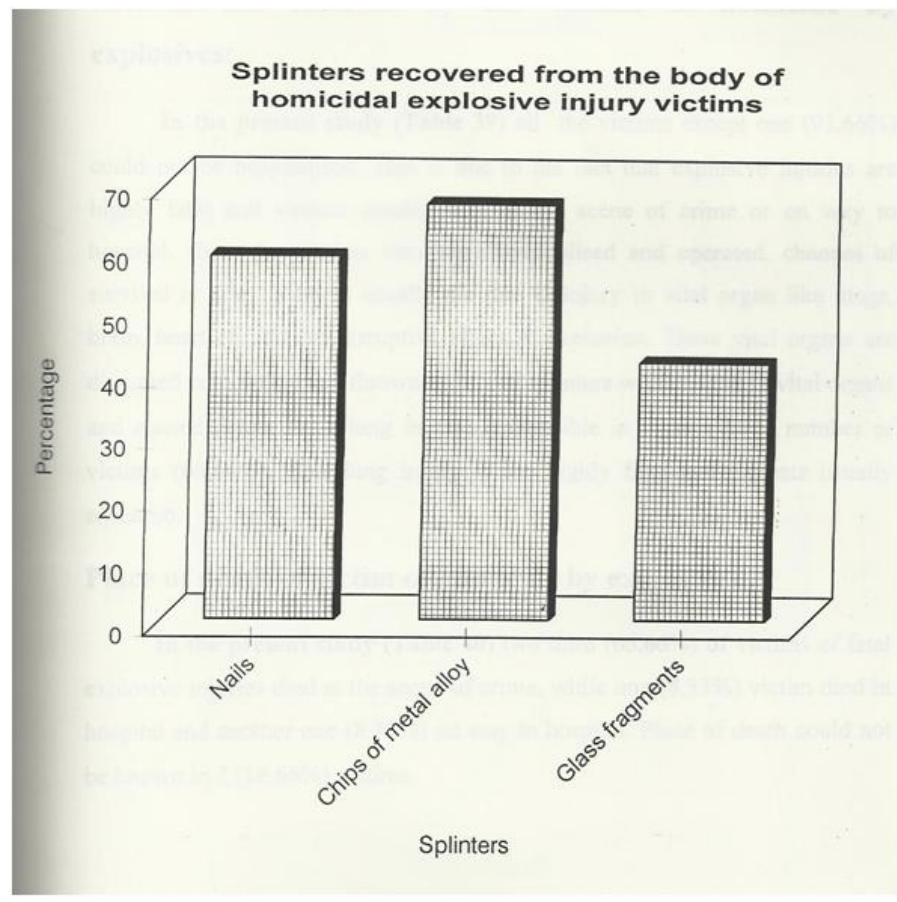

Medical aid received by the victims of homicide by explosives: In the present study (Table 9) all the victims except one (91.66\%) could not be hospitalised. This is due to the fact that explosive injuries are highly fatal and victims usually died at the scene of crime or on way to hospital. Even the victims who were hospitalised and operated, chances of survival is grim. Victims usually die due to injury to vital organ like lungs, brain, heart etc. due to disruptive effect of explosion. These vital organs are disrupted completely and thrown apart and splinters were lodged in vital organs and caused death. Blast lung in also responsible in quite a large number of victims (66.66\%). This lung injury is too highly fatal and patients usually succumb.

Place of death of victim of homicide by explosives: In the present study (Table 10) two third $(66.66 \%)$ of victims of fatal explosive injuries died at the scene of crime, while one (8.33\%) victim died in hospital and another one (8.33\%) on way to hospital. Place of death could not be known in 2 (16.66\%) victims. 


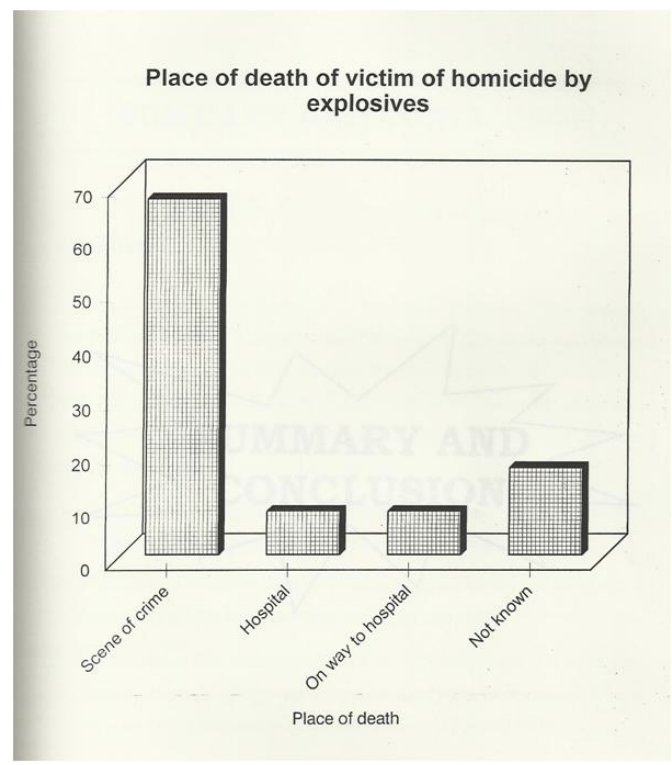

\section{SUMMARY AND CONCLUSION:}

Summary: One hundred cases of homicide by firearm and explosive drawn from the medicolegal autopsies in the mortuary of Department of Forensic Medicine, Institute of Medical Sciences, Banaras Hindu University, Varanasi, U.P. India during the period from 1st July, 1999 to 30th November 2000, were studied with focus on wounds and medicolegal aspect. The important findings of the study are summarised as under:

1. Gunshot entry wounds were present in all (100\%) the victim of homicide by firearms while exit wounds were seen in over majority of victims (61.36\%).

2. No any exit wound was present in over one third (38.63\%) cases.

3. In maximum (46.59\%) victims brain and meninges were involved followed by involvement of pleura and lungs $(20.45 \%)$.

4. In all the victim of fatal explosive injuries (100\%), burnings, abrasions, laceration and contusions were seen.

5. Associated injuries by weapons other than explosives were absent in three fourth (75\%) victims of fatal explosive injuries.

6. All victims of homicide by explosives (100\%) had injuries on multiple body parts.

7. Pleura and lungs were involved in most (83.33\%) of the homicidal explosive victims followed by pericardium and heart (75\%).

8. Chips of metal alloy were recovered from the body of fatal explosive injury victim in two third $(66.66 \%)$ cases followed by recovery of nails (58.33\%).

9. Most of the victims (91.66\%) of homicide by explosives could not be hospitalised .

10. Two third (66.66\%) of victims of homicide by explosives died at the scene of crime.

CONCLUSION: There has been a phenomenal rise in the use of firearms and explosives for committing various crimes leading to death of victims. This spurt in its use may be attributed to the deteriorating socio-economic, and law and order situation as also easy availability of both licit and illicit as well as improvised or country made firearms and bombs all over India. 
But in view of the complexities created by the introduction of newer and newer improvised and conventional firearms and explosives in most of the areas, the establishment of various facts in a cases of firearm death, such as the type of weapon used, the range of firing, the direction of fire, the number of shots fired, wound of entry and exit and the damage to vital parts and the like, have become fraught with many difficulties and complexities for the Forensic Pathologists as also for the Ballistic Experts.

\section{BIBLIOGRAPHY:}

1. Adelson L. (1953): Medical Evidence in Fatal Gunshot Injuries. Am. J. Clin. Path. 23:758-767.

2. Adelson L. (1961): A Microscopic Study of Dermal Gunshot Wound s. Am. J. Clin. Path. 35 : 393 402.

3. Adelson L. (1974): Pathology of Homicide. Edn. Charles Thomas Publisher. 188-318.

4. Andrasko J. and Machly A.C. (1977): Detection of Gunshot Residues on Hands by Scanning Election Microscopy. Jr. Fors. Scs. 22(3): 279-287.

5. Asgakar M.D. et al. (1972): Determination of Gunshot Firing Distances. Arkiv. Jur. Krim. 149:1975.

6. Devasia, V.V. and Devasia, L. (1985): The Phenomenon of Criminal Homicide. Indian J. Criminology and Criminalistics. 3-4:142-146.

7. Devasia, V.V. and Devasia, Leelamma (1982): "Sexual Behaviour of Male Prison Inmates Convicted of Criminal Homicide". Indian J. Criminology and Criminalistics. 2-4:192-196.

8. DiMaio V.J.M. and DiMaio D.J. (1972): Bullet Embolism Six Cases and a Review of the Literature. J. For. Sci. 17:394.

9. DiMaio V.J.M. and Spitz, W.U. (1972): Variations in wounding due to unusual firearm and recently available ammunition. J. Forensic Sci. 17:377.

10. Durkheim, E. (1897); Le, Suicide, Paris : Felix Alcon. Quoted by Lester D. (1992). Can there be a Durkheimian Theory of Homicide ? Indian J. Criminology. 20(2):

11. Durkheim, E.A. (1893). The Division of Labour in Society. Translated by G. Simpson Free Press, 1933.

12. Eckert William G. (1977) : Homicidal and Suicidal Deaths in Forensic Medicine Edited by C.G. Tedeschi, W.G. Eckert and Luke G. Tedeschi, Vol. II, Chapter 43, W.B. Saunders Company, pp. 1004-1014.

13. Gibbens T.C.N. (1958): Sane and Insane Homicide. The Jr. Crim Law, Criminology and Police Sci. 49(2):110-115.

14. Gilmore 1I.R (1954): Medical Aspects of the Assassination of Abraham Lincoln. Proc. R. Soc. Med. 47:103. i

15. Graham J.W., Patty C.B., Flohr D.M. and Peterson W. (1966): Forensic Aspect of Frangible Bullets. J. For. Sci. 11:507.

16. Guerin P.F. (1960). Shotgun Wounds J. Fors. Sci. 5:294.

17. Gupta A.K., Das Gupta S.M. and Rastogi B.L. (1979): Study of Injuries from Firearm in Medicolegal Autopsies. Thesis Submitted for the Degree of Doctor of Medicine (Forensic Medicine), Institute of Medical Science, B.H.U., Varanasi.

18. Kelly G et al. (1978): The Continuing Challenge of Duodenal Injuries. Jr. Trauma. 18 (3):160. 
19. Kiel W. (1973): Homicides in Germany Involving the American Army. Legal Medicine Annual Wecht C. Edn. Appleton Century Crofts.

20. Kirk P. (1953): Crime Investigation. Interscience Publisher Inc. New York. pp. 353.

21. Knight B. (1958): Fatal Gunshot Wounds. Criminologist. 3:31.

22. Knight B. (1976): Injuries from Firearm and Explosives Practitioner. 217(1302): 975-982.

23. Kracke A.D. (1963): Jour. Pedist. 63:1184.

24. Parikh's Simplified Text Book of Medical Jurisprudence and Toxicology. Partkh C.K.,Edn., 1983.

25. Personal Communication with the Caretaker Ramnagar Fort, Fort Museum Near Varanasi.

26. Petty C.S. (1969): Firearms Injury Research : The Role of the Practicing Pathologist. Am. J. Clin. Pathol. 52:277.

27. Piedlievers R. and Nichon R. (1957): A Study of Gunshot Wound Formation. Postgrad. Med. 22:A-34.

28. Pokorny Alex D. (1965): A Comparison of Homicide in the Two Cities. The Jr. of Crim. Law, Criminology and Police Science. 56(4):479-487.

29. Pokorny Alex D. (1965): Human Violence : A Comparison of Homicide, Aggravated Assault, Suicide and Attempted Suicide. The Jr. of Crim. Law, Criminology and Police Science. 56(4):488-497.

30. Pokorny, Alex D. (1965). A Comparison of Homicide in Two Cities. The Jl. of Criminal Law Criminology and Police Sci. 56(4):479-487.

31. Poison C.J. and Gee D.J. (1973): The Essential of Forensic Medicine. $3^{\text {rd }}$ Edn. Pergamon Press, pp. 204-260.

32. Pramley L.F., Mattingly T.W. and Manion W.C. (1958): Penetrating Wounds of Heart an Sorts. Circulation. 17:953.

33. Rai, S.P. (1987): Thesis Submitted for A Study of Homicide by Blunt Violent in Medicolegal Autopsy.

34. Rajan V.N. and Krishna K.P. (1981): Victims of Homicide. The Indian Jr. of Criminology and Criminalisation, Vol. I, No. 4, Institute of Criminology and Forensic Science, Ministry of Home Affairs, Govt, of India, pp. 154-158.

35. Spitz W.U., Petty C.S. and Fisher R.S. (1961): Physical Activity Until Collapse Following Fatal Injury by Firearms and Sharp Weapons. Jr. Forensic Sci. 6:290.

36. Sturner W.C. and Petty C.S. (1973): Firearm Injuries Modern Trends in Forensic Medicine. 3 rd Edn. A.K. Mant. Butterworth, Chapter 6.

37. Subrahmanyam B.V., Das Gupta S.M., Rao CM. and Kaviya V.D. (1978): Epidomiologia Firearm Fatalities. Jr. Ind. Acad. For. Sci. 17(1):57-63.

38. Subrahmanyam, B.V., Das Gupta, S.M., Rao, CM. and Kavita, V.D. (1978): Epidemiological Firearm Fatalities Jl. Indian Acad. Fer. Sci. 17:1.

39. Subramanyam B.V., Das Gupta S.M. and Gupta A.K. (1978): Unusual Firearm Fatalities - Paper Presented at the $2^{\text {nd }}$ Annual Conference of Indian Academy of Forensic Medicine.

40. Taylor's Principles and Practice of Medical Jurisprudence 12th Edn. Edited by Simpson K., 1965 J \& A Churchill Ltd. pp. 282-315.

41. Tedeschi, C.G., Eckert, W.G. and Luka, G. Tedeschi (1977). Forensic Medicine. Vol. 1, WB, Saunder Company, Philadelphia London, Toranto, pp. 29-61. 
42. Venugopal Rao - Facets of Crime in India. Allied Publishers New Delhi p. 172.. Bur eau of Police Research and Develop Development III, 1983 p. 1-4

43. Voss, Harwin L and Hepburn John R. (1968). Patterns in Criminal Homicide in Cicago. The Jl. of Criminal Law Criminology and Police Sci. 59(4):499-508.

44. Walker J.T. (1940): Bullet Holes and Chemical Residues in Shooting Cases. J. Crim. Law and Criminol. 31:497.

45. Walker J.T. (1949): Further Observations on the Diphenylamine Test for Gun Powder Residue. Internat. Assoc, for Indet. Proceedings, 34'" Annual Conventional pp. 187.

\section{AUTHORS:}

1. Rajeev Kumar

\section{PARTICULARS OF CONTRIBUTORS:}

1. Professor \& Head, Department of Forensic Medicine \& Toxicology, Gold Field Ins titute of Medical Sciences \& Research, Chhainsa, Ballabgarh, Faridabad.

\section{NAME ADDRESS EMAIL ID OF THE} CORRESPONDING AUTHOR:

\section{Dr. Rajeev Kumar,}

Professor,

House No. $-877,2^{\text {nd }}$ Floor,

Sector - 40, Gurgaon, PIN - 122001.

Email - rajeevkyam@gm ail.com

Date of Submission: 24/09/2013.

Date of Peer Review: 05/10/2013.

Date of Acceptance: 22/10/2013.

Date of Publishing: 29/10/2013 